\title{
What's in a Head? Comparative Morphology of Head Muscles in the Three Drusinae Clades (Insecta: Trichoptera)
}

Carina Zittra ( $\square$ carina.zittra@univie.ac.at )

University of Vienna

\section{Simon Vitecek}

University of Natural Resources and Life Sciences

Thomas Schwaha

University of Vienna

Stephan Handschuh

Vetmeduni Vienna

Jan Martini

University of Innsbruck

Ariane Vieira

TU Wien

Hendrik C. Kuhlmann

TU Wien

Johann Waringer

University of Vienna

\section{Research Article}

Keywords: subfamily Drusinae, larval stages, omnivorous shredders sharing rounded head capsules

Posted Date: June 17th, 2021

DOI: https://doi.org/10.21203/rs.3.rs-618759/v1

License: (1) (1) This work is licensed under a Creative Commons Attribution 4.0 International License. Read Full License 


\section{Abstract}

The subfamily Drusinae (Limnephilidae, Trichoptera) comprises a range of species exhibiting differently shaped head capsules in their larval stages. These correspond to evolutionary lineages pursuing different larval feeding ecologies, each of which uses a different hydraulic niche: scraping grazers and omnivorous shredders sharing rounded head capsules and filtering carnivores with indented and corrugated head capsules. In this study, we assess whether changes in head capsule morphology are reflected by changes in internal anatomy of Drusinae heads. To this end, internal and external head morphology was visualized using $\mu C T$ methods and histological sections in three Drusinae species - Drusus bosnicus, $D$. franzi and $D$. discolor - representing the three evolutionary lineages. Our results indicate that Drusinae head musculature is highly conserved across the evolutionary lineages with only minute changes between taxa. Conversely, the tentorium is reduced in $D$. discolor, the species with the most aberrant head capsule investigated here. Integrating previous research on Drusinae head anatomy, we propose a fundamental Drusinae blueprint comprising 29 cephalic muscles and discuss significance of larval head capsule corrugation in Trichoptera.

\section{Introduction}

Nature comes in manifold color, smell, shape, and taste. As in all other life forms a great variety of different morphologies can be observed in aquatic insects as well ${ }^{1}$. Differences in morphology typically are accompanied by a distinct ecological niche, related to - for instance - feeding mode ${ }^{2}$. Predators among aquatic insects may enjoy prehensile mouthparts, or a slender agile body that allows them to pounce on their prey ${ }^{3}$. Grazers have developed their mouthparts to an intricate array of brushes and bristles to scrape off benthic algae ${ }^{3}$. Passive filter-feeders, on the other hand, often have elongated antennae or legs equipped with bristles to collect food particles from the flow ${ }^{3}$. And those among aquatic insects feeding on larger detritus, the so-called shredders, often are rather bland but equipped with robust mandibles to masticate their food ${ }^{3}$.

Naturally, species of these functional feeding groups occur in different regions in a local habitat following the distribution of food sources in the stream bed ${ }^{2}$. Predators can pick any spot if prey densities are high enough, but grazers, filter feeders and shredders need to select specific habitat spots to maximize feeding efficiency ${ }^{4-7}$. These microhabitats are most importantly defined by distinct flow velocities: at slowly flowing sections detritus accumulates whereas benthic algae grow most densely at the upper sides of large stones in faster waters, where also food particle density in the drift is high ${ }^{8-12}$.

Consequently, astounding adaptations to hydraulic stress can be observed in aquatic insects in addition to those enforced by feeding modes. In caddisflies, behavioural adaptations include the use of silk as safety tether in Rhyacophilidae, Hydropsychidae and Brachycentridae, ballast stones in Goeridae ${ }^{4}$, and a silken stalk in Limnocentropodidae ${ }^{3}$. Conversely, morphological adaptations to hydraulic stress are rarely considered in caddisflies. The bodies of other aquatic insects are in contrast often modified to suit a 
particular purpose: the reduction of hydraulic stress. This is demonstrated by the flattened, streamlined bodies of Heptageniidae that certainly are at the pinnacle of morphological adaptation to hydraulic stress $^{3}$.

Recently, head capsule morphology was identified as potential adaptation to hydraulic stress and a particular feeding mode in Drusinae caddisflies ${ }^{13}$. The Drusinae are an intriguing group of Limnephilidae, and comprise three distinct evolutionary clades. Each of these clades comprises species sharing a particular larval feeding ecology: scraping grazers with toothless mandibles, and filtering carnivores and shredders with tooth-bearing mandibles. While evolutionary relationships between these clades remain to be clarified, comparative morphological analyses based on adults indicate that Drusinae shredders may have retained ancestral characters ${ }^{14}$. Drusinae likely diversified in vicariant conditions under the impact of repeated cold ages and geological processes with scraping grazers representing the greatest radiation of the group. Extant Drusinae bear mark of their evolutionary background and develop adult and larval characters that indicate to which feeding group each species belongs ${ }^{13}$. In Drusinae larvae, head capsule morphology is of particular importance: head capsules of species of the filtering carnivore clade differ strikingly from the rounded head capsules of their congeners and other European Limnephilidae ${ }^{13}$. The significance of head capsule shape for their ecology remains unclear, but a link to feeding ecology was recently proposed. And while the cephalic anatomy of Drusus trifidus and D. monticola is known ${ }^{15,16}$, there is to date no information whether these scraping grazer species can serve as blueprint for all Drusinae, including shredders and the filtering carnivores with their peculiar heads (Fig. 1).

We propose that the aberrant forms of filtering carnivore Drusinae heads are reflected in modifications of the internal anatomy, which, in turn, correspond to different evolutionary trends within Drusinae. To address our hypotheses, we use a sample of three different species comprising a shredder $(D$. franzi), a filtering carnivore ( $D$. discolor) and a scraping grazer ( $D$. bosnicus), and integrate available information on $D$. trifidus and $D$. monticola. We hypothesize that location and number (or volume) of head muscles differs between shredder, scraping grazer, and filtering carnivore Drusinae. In particular, we posit that the shredder species will have the most complex internal organization, and that shifts in attachment sites as well as numbers of muscles occur in grazers and filtering carnivores.

\section{Results}

Our first aim was to define a generalized Drusinae head. We found, in brief, the general Drusinae head bauplan to comprise a tentorium with 2 branches and a set of 29 cephalic muscles to operate mouthparts and the alimentary canal (Fig. 2-5). The largest muscles in the Drusinae head operate the mandibles: the Musculus cranio-mandibularis medialis (1, the adductor) and the $\mathrm{M}$. cranio-mandibularis lateralis (2, the abductor); an additional mandibular muscle originates from the tentorium (M. tentoriomandibularis; 13). From the frontoclypeus, three pairs of muscles originate that insert in the labrum (M. fronto-labralis; 3 ), the pharynx (M. fronto-pharyngalis; 4) and the epipharynx (M. fronto-epipharyngalis; 5 ). The maxillolabium has four pairs of intrinsic muscles: The M. praemento-salivaris (7), the M. 
hypopharyngosalivaris (8), the M. basistipido-dististipitalis lateralis (9), and the M. basistipidodististipitalis medialis (10). Further, a set of muscles originates from the tentorium and comprises the M. tentorio-stipitalis (11) and the M. tentorio-cardinalis (12) that insert in the maxillolabium at stipes/cardo, and the M. tentorio-mandibularis (13) (Fig. 5). Close to the base of the tentorium, three muscles originate that also insert in the maxillolabium: The M. cranio-dististipitalis (14), the M. cranio-praementalis anterior (15) and the M. cranio-praementalis lateralis (16). Aside these muscle groups that grant movement to the mouthparts, the alimentary canal is operated and held in position by several thin muscle bundle pairs. At the ventral side of the pharynx insert the M. cranio-cibialis (17), the M. cranio-pharyngalis anterior and posterior $(18,19)$, and the M. cranio-esophagialis $(20)$. Dorsally, function and position of the alimentary canal is supported by the M. labro-epipharyngalis (21), the M. parieto-pharyngalis lateralis (22), the M. fronto-pharyngalis medialis (23), the M. fronto-pharyngalis lateralis (24), the M. fronto-pharyngalis ventralis $(25[25,26$; split into two muscle bundles in $D$. discolor]), the M. clypealis-pharyngalis (split into two muscle bundles; 27, 28), and the M. clypealis-cibarialis (split into two muscle bundles; 29, 30) in front of the brain, and the M. parietalis-oesophagialis (6) behind the brain.

Our second aim was to compare internal head anatomy between Drusinae clades. Despite the impressive differences in head capsule shape, each of the three species investigated here shares the same set of cephalic muscles, with only minute differences in the location of single points of origin of, e.g., frontal muscles (Fig. 5, 6). In particular, the points of origin relative to the M. fronto-labralis and the number of individual muscle bundles of the M. fronto-epipharyngalis differs between the species as well as the points of origin of the $\mathrm{M}$. fronto-pharyngalis relative to the M. fronto-labralis. In $D$. franzi, the points of origin are arranged sequentially along the dorso-ventral plane in the following order: $M$ fronto-labralis, $M$ fronto-pharyngalis, M. fronto-epipharyngalis. In $D$. discolor, the same order of points of origin can be observed, where the M. fronto-pharyngalis is located somewhat closer to the M. fronto-pharyngalis, and the M. fronto-epipharyngalis has more than one point of origin on either side. Drusus bosnicus displays a different configuration where the dorsalmost points of origin of the M. fronto-labralis, the M. frontopharyngalis and the $\mathrm{M}$. fronto-epipharyngalis are in roughly the same dorsoventral plane, the $\mathrm{M}$. frontopharyngalis has more than one point of origin on either side, and the M. fronto-epipharyngalis has several points of origin that are located obliquely in sequence from the dorsalmost point of origin. Further, $D$. discolor exhibits a doubled M. fronto-pharyngalis and the points of origin of some muscle bundles of the M. cranio-mandibularis medialis differs between $D$. discolor and the two other investigated species. (Fig. 2-4). In contrast, all other muscles including those of the alimentary canal and the maxillolabium are highly similar in all three species (Fig. 5-6). The only apparent internal change induced by the aberrant head morphology in $D$. discolor pertains to the tentoria, which lack a complete secondary supratentorial branch that is present in $D$. franzi as well as D. bosnicus (Fig. 5-7).

\section{Discussion}

Head anatomy of the Drusinae appears to be highly conserved. The number and arrangement of head muscles are virtually identical in all hitherto investigated Drusinae species ${ }^{15,16}$. The duplication of a 
muscle pair in $D$. discolor (M. fronto-pharyngalis ventralis) is be the only recognizable difference. Functionally, an engorging facultative predator such as $D$. discolor could benefit from greater mobility of the pharynx, but whether a single duplication or a somewhat larger volume of alimentary canal muscles can have that effect is doubtful. Differences in muscle volumes however could reflect feeding ecology of Drusinae shredders and scraping grazers. Drusus franzi relies on a recalcitrant food source may have relatively large mandible adductors that could enable stronger bites. Scraping grazers may be more limited in their food uptake by the number of scraping movements per unit time and larger mandible abductors in $D$. bosnicus may be an adaptation to this feeding mode by allowing for more scraping movements per unit time. While more comprehensive studies remain to be conducted, the preliminary data obtained here point towards the possibility that such volumetric differences can be observed: Mandible adductors make up for roughly $85 \%$ of the total reconstructed head muscle volume in $D$. franzi, $77 \%$ in $D$. discolor and $72 \%$ in $D$. bosnicus. At the same time our provisional summary found the greatest mandible abductor muscle volume in $D$. bosnicus ( $12 \%$ of the total head muscle volume), and $D$. discolor as having the greatest alimentary canal muscle volume ( $9 \%$ of total head muscle volume). These rough figures may be a first indication for such a differentiation, but should not be trusted until verified in a larger, more standardized sample.

Drusinae head anatomy was first investigated in D. trifidus, a representative of the Drusinae grazer clade $^{15}$. Data on another Drusinae grazer species, $D$. monticola, suggested high congruence of this species with the previously described situs ${ }^{16}$ but did not cover other evolutionary lineages of Drusinae. Here, we present evidence contrary to our initial hypotheses, suggesting largely identical head muscle number and arrangements in all three major evolutionary lineages of Drusinae with minor deviations in the filtering carnivore clade. Interestingly, the configuration of frontal muscles in the Drusinae grazer clade observed in $D$. bosnicus was also observed in $D$. monticola. While it is probable that $D$. trifidus exhibits the same pattern, the available data do not allow for an assessment. Whether this configuration is typical for Drusinae scraping grazer remains to be evaluated, but this notion is conceivable because of the close relationships within this clade ${ }^{13,17}$.

Concerning the internal head skeleton, the tentorium, we posit that the changes of head shape in $D$. discolor and other filtering carnivorous Drusinae ${ }^{13}$ induce modifications such as the increasing simplification of the tentorium. In this regard, we assume that the modified head capsules of the filtering carnivore Drusinae offer greater mechanical stability due to their structured surface as compared to the rounded head capsules of the other Drusinae - thus, the second branch of the tentorium is superfluous and can be reduced. We base this interpretation on the observed mechanical properties of corrugated bodies, that are capable of withstanding greater forces ${ }^{18,19}$. In-field measurements indicate that filtering carnivore larvae occupy microhabitats where hydraulic stress is higher compared to other Drusinae ${ }^{20}$. Adaptations increasing stability of particularly exposed body parts such as a corrugated head capsule may prove beneficial under such circumstances. However, head capsule shape in filtering carnivore Drusinae was previously interpreted in relation to flow modification around the larval head and feeding ecology. Flow patterns around Drusinae larval heads are the focus of ongoing research (Vieira et al. 
unpubl.), but comparative analyses of mechanical properties of Drusinae head capsules remain to be conducted.

From a systematist point of view, the reduced second arm of Drusinae tentoria could be, pending further studies, a synapormorphy accompanying head capsule modification in this clade, opposed to a potentially plesiomorphic biramal tentorium of the Drusinae common ancestor.

The lack of differences in the internal anatomy of Drusinae heads that differ strongly in their outer head capsule morphology is surprising. We present the first data on a caddisfly larva with an aberrant head capsule shape, but if our findings apply to other taxa as well remains to be investigated. A wide range of Trichoptera taxa develop larvae in which the head capsules are not in a simple round shape. Amongst the European Trichoptera, Lithax niger is certainly one of the most distinctive forms, but to date no comparative morphological studies are present of this species. Likewise, there are no anatomical treatments on other species with aberrant head shapes. A suite of potential model taxa of Brachycentridae (Micrasema), Beraeidae (Beraea), Goeridae (Silo, Goera, Lithax), Limnephilidae (filtering carnivorous Drusus, Philocasca, Pseudostenophylax), Rossianidae (Goeriella), Apataniidae (Allomya) and Hydropsychidae (e.g., H. tabacarui) develop larval heads distinctly different from the rounded ones sported by their congeners. Whether the minor impact of head capsule modification on internal head anatomy can be confirmed in other taxa as well will be subject of future studies. The absence of major changes however suggests that head capsule modification is not a costly means of adaptation to specific habitats. Conversely, any change in cephalic musculature will inevitably affect feeding, gut movement or size and configuration of the central nervous system. Modified head capsules as observed in some Drusinae but also in other groups can therefore probably evolve quickly and at low evolutionary costs if less important areas of the cephalic exoskeleton are involved. Intriguingly, anecdotal evidence suggests that some other Trichoptera larvae with modified head capsules use high-stress hydraulic niches (e.g. Allomya, pers. comm. J.J. Giersch).

Embryonic development of insect heads involves the formation of parietals and the frontoclypeus following a "bend and zipper" model ${ }^{21}$. Head appendage tissue (with the exception of the labrum) is not involved in this process, and the corresponding muscles are mesodermal derivates that make contact with the epidermis during embryonic development ${ }^{21,22}$. Developmental gene expression regulates head capsule formation and shape, where gnathal appendages are formed under influence of pair-rule and Hox genes $^{21}$. Processes and developmental genes controlling head capsule shape in Trichoptera are not known. Evidence from other insects with head capsule modifications, such as Scarabaeidae, suggest that sets of developmental factors are co-opted to act as controlling agents in horn formation ${ }^{23,24}$.

Assuming that the same or highly similar molecular controls of head capsule shape are used across the more homogeneous Trichoptera is therefore plausible. However, exact patterning and developmental mechanisms, and how development of species-specific head capsule shapes is maintained over time, remains obscure. In particular comparative assessments within Drusinae as well as between different caddisfly families should be made to clarify the genomic background of head capsule corrugation and 
indentation. Most probably the same genes are involved in different families, but how exactly head capsule shapes take form during development and which ecological function head capsule shape and corrugation have is enigmatic. Available data on Drusinae hydraulic niches suggest that head capsule corrugation may be linked with high-stress microhabitats optimal for filter-feeding ${ }^{20}$. In other taxa (e.g. Goeridae, Brachycentridae, Apataniidae, etc.) head capsule corrugation and indentation may be the result of similar ecological constraints.

\section{Methods}

\section{Sample preparation}

Three Drusinae specimens of three different feeding and evolutionary clades, Drusus bosnicus, D. discolor and $D$. franzi, were used for $\mu C T$ analysis. Drusus discolor was collected in the Schreierbach near Lunz

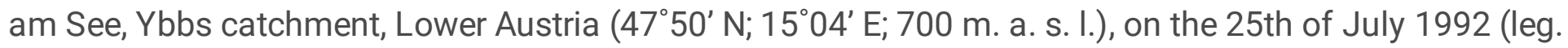
Johann Waringer). Drusus bosnicus was collected in the Paljanska Miljacka River, Bosnia-Herzegowina $2008,\left(43^{\circ} 49^{\prime} \mathrm{N} ; 18^{\circ} 32^{\prime} \mathrm{E} ; 848\right.$ m. a. s. I.) on 17th of May (leg. M. Kucinic).

Drusus franzi was collected at the Saualpe, Carinthia, Austria $\left(46^{\circ} 50^{\prime} \mathrm{N} ; 14^{\circ} 40^{\prime} \mathrm{E} ; 1665 \mathrm{~m}\right.$. a. s. I.) on the 29th of May 2006 (leg. P. Wenzl). All samples were stored in 90\% ethanol.

\section{$\mu$ CT scanning}

For $\mu \mathrm{CT}$ analysis, larvae were stained for 21 days in $1 \%(\mathrm{w} / \mathrm{v})$ phosphotungstic acid (PTA) in 70\% ethanol and washed in in $70 \%$ ethanol to remove unbound PTA from tissue. Afterwards, the larvae were mounted vertically in $70 \%$ ethanol in the tip of a plastic pipette, and sealed in with parafilm. Larvae were scanned on an XRadia MicroXCT-400 (Carl Zeiss X-ray Microscopy, Pleasanton, CA, USA) at $80 \mathrm{kVp} / 100 \mu \mathrm{A}$ using the $4 \mathrm{X}$ detector assembly. Projections were recorded with 15 s exposure time (camera binning $=1$ ) and an angular increment of $0.225^{\circ}$ between projections over a $360^{\circ}$ rotation. Tomographic slices were reconstructed with a voxel resolution of $2.87 \mu \mathrm{m}$ (reconstruction binning $=1$ ) using the XMReconstructer software provided with the $\mu \mathrm{CT}$ system.

\section{Image processing}

The merged volume was exported as *.TXM file into Amira 2019.1 (FEI SAS, Mérignac, France (part of Thermo Fisher Scientifi $\left.C^{\top \mathrm{T}}\right)$ )). A 3D bilateral filter was used to filter the image volume for noise reduction. Image segmentation was achieved in Amira 6.5.0 (Visage Imaging, Inc., San Diego, CA, USA). Internal head anatomy (head muscles, tentoria, central nervous system including cerebral ganglion mass, gnathal ganglion mass, frontal ganglion and innervation patterns) were manually segmented and assigned to different "materials" within the segmentation editor. Three-dimensional surface renderings were created based on this manual segmentation using the Amira Surface Generate tool. 


\section{Histology, computer-based 3D reconstruction and post processing}

Heads of $D$. bosnicus and $D$. discolor were cut off from the remaining body for histological processing. First samples were dehydrated with acidified dimethoxypropane followed by three rinses with acetone before being infiltrated and embedded in Agar LVR resin (Agar Scientific, Stansted, UK). Cure resin blocks were serially sectioned with a Diatome HistoJumbo diamond knife (Diatome, Nidau, Switzerland) at $1 \mu \mathrm{m}$ section thickness on a Leica UC6 ultramicrotome (Leica microsystems, Wetzlar Germany). Sections were stained with $1 \%$ toluidine blue and sealed in epoxy resin. Analysis and photography of the serial sections was conducted on Nikon NiU compound microscope with a Nikon DsRi2 microscope camera (Nikon, Tokyo, Japan).

Image stacks were converted to greyscales and contrast-enhanced with F:IJ| $\left.\right|^{25}$ and subsequently imported into the visualization software Amira 2020.2 (ThermoFisher). Alignment of consecutive sections was conducted with the AlignSlices Tool of Amira. Structures of interest (tentorium, nervous system and digestive tract) were semi-manually reconstructed by labelling with a brush and interpolating of a several consecutive sections. Surfaces were calculated from the segmentation masks, followed by surface optimization by iterated smoothing and polygon-reduction steps. Snapshots were taken with the Amira software.

\section{Declarations}

\section{Acknowledgements}

This research was supported using resources of the VetCore Facility (imaging) of the University of Veterinary Medicine Vienna and the Department of Evolutionary Biology (histology) of the University of Vienna.

Author Contributions: C. Z. and S. V. prepared the samples, drafted main text, reconstructed head anatomy, analyzed the data, S. V. prepared figure 1, T. S. conducted histological sections, prepared figures 2-7, S.H. conducted $\mu$ CT scanning, analyzed the data, J.W. acquired the samples and designed and conceptualized the study. J.W. and H. C. K. critically reviewed the manuscript, funding acquisition. All authors reviewed, edited and commented draft versions of the manuscript and approved of the final manuscript version.

\section{Competing interests}

The authors declare no competing interests.

\section{Data availability}

All data generated or analyzed during this study are included in this published article: 


\section{Funding}

This manuscript includes results of the project "Intricate bodies in the boundary layer" (project number P31258-B29, PIs: J. Waringer, H. Kuhlmann) funded by the Austrian Science Fund (FWF).

\section{References}

1. Thorp, J. H. \& Rogers, D. C. Thorp and Covich's Freshwater Invertebrates. (Elsevier, 2015). doi:10.1016/C2010-0-65590-8.

2. Cummins, K. W. \& Klug, M. J. Feeding Ecology of Stream Invertebrates. Annual Review of Ecology and Systematics 1, 147-172 (1979).

3. Wichard, W., Arens, W. \& Eisenbeis, G. Atlas zur Biologie der Wasserinsekten. (Springer Berlin Heidelberg, 1999). doi:10.1007/978-3-642-39452-2.

4. König, E. \& Waringer, J. The ballast stones in Silo nigricomis cases (Insecta: Trichoptera): drift resistance and ecological benefits, investigated by acoustic Doppler velocimetry. rs 18, 311-328 (2008).

5. Bohle, H. W. Drift-fangende Köcherfliegen-Larven unter den Drusinae (Trichoptera: Limnephilidae). entomologia 12, 119-132 (1987).

6. Wetmore, S. H., Mackay, R. J. \& Newbury, R. W. Characterization of the Hydraulic Habitat of Brachycentrus occidentalis, a Filter-Feeding Caddisfly. Journal of the North American Benthological Society $9,157-169$ (1990).

7. Wallace, J. B. \& Merritt, R. W. Filter-Feeding Ecology of Aquatic Insects. Annu. Rev. Entomol. 25, 103-132 (1980).

8. Biggs, B. J. F. Hydraulic Habitat of Plants in Streams. Regulated Rivers: Research \& Management 12, 131-144 (1996).

9. Biggs, B. J. F., Goring, D. G. \& Nikora, V. I. Subsidy and stress responses of stream periphyton to gradients of water velocity as a function of community growth form. $J$ Phyco/ 34, 598-607 (1998).

10. Biggs, B. J. F. \& Smith, R. A. Taxonomic richness of stream benthic algae: Effects of flood disturbance and nutrients. Limnology and Oceanography 47, 1175-1186 (2002).

11. Miliša, M., Habdija, I., Primc-Habdija, B., Radanović, I. \& Kepčija, R. M. The Role of Flow Velocity in the Vertical Distribution of Particulate Organic Matter on Moss-covered Travertine Barriers of the Plitvice Lakes (Croatia). Hydrobiologia 553, 231-243 (2006).

12. Waringer, J. A. The drifting of invertebrates and particulate organic matter in an Austrian mountain brook. Freshwater Biology 27, 367-378 (1992). 
13. Vitecek, S. et al. A hairy case: The evolution of filtering carnivorous Drusinae (Limnephilidae, Trichoptera). Molecular Phylogenetics and Evolution 93, 249-260 (2015).

14. Vitecek, S. Phylogenetic analysis of the Drusinae subfamily (Insecta, Trichoptera). (Universität Wien, 2015).

15. Fotius-Jaboulet, M.-C. Squelette et musculature cephaliques de la larve de Drusus trifidus (Trichoptera-Limnephilidae). Travaux du Laboratoire de Zoologie et de la Station Aquicole Grimaldi de la Faculté des Sciences de Dijon 40, 1-79 (1961).

16. Zittra, C. et al. External and internal head anatomy of Drusus monticola (Trichoptera, Limnephilidae). Entomologica Austriaca 28, 119-131 (2021).

17. Vitecek, S. et al. Integrative taxonomy by molecular species delimitation: multi-locus data corroborate a new species of Balkan Drusinae micro-endemics. BMC Evol Biol 17, 129 (2017).

18. Ha, N. S. \& Lu, G. Thin-walled corrugated structures: A review of crashworthiness designs and energy absorption characteristics. Thin-Walled Structures 157, 106995 (2020).

19. Eyvazian, A., Akbarzadeh, I. \& Shakeri, M. Experimental study of corrugated tubes under lateral loading. Proceedings of the Institution of Mechanical Engineers, Part L: Journal of Materials: Design and Applications 226, 109-118 (2012).

20. Waringer, J. et al. Hydraulic niche utilization by larvae of the three Drusinae clades (Insecta: Trichoptera). Biologia (2020) doi:10.2478/s11756-020-00648-y.

21. Posnien, N., Schinko, J. B., Kittelmann, S. \& Bucher, G. Genetics, development and composition of the insect head - A beetle's view. Arthropod Structure \& Development 39, 399-410 (2010).

22. Bate, M. The embryonic development of larval muscles in Drosophila. Development 110, 791-804 (1990).

23. Ohde, T. et al. Rhinoceros beetle horn development reveals deep parallels with dung beetles. PLOS Genetics 14, e1007651 (2018).

24. Adachi, H., Matsuda, K., Niimi, T., Kondo, S. \& Gotoh, H. Genetical control of 2D pattern and depth of the primordial furrow that prefigures 3D shape of the rhinoceros beetle horn. Scientific Reports 10, 18687 (2020).

25. Schindelin, J. et al. Fiji: an open-source platform for biological-image analysis. Nature Methods 9 , 676-682 (2012).

\section{Figures}




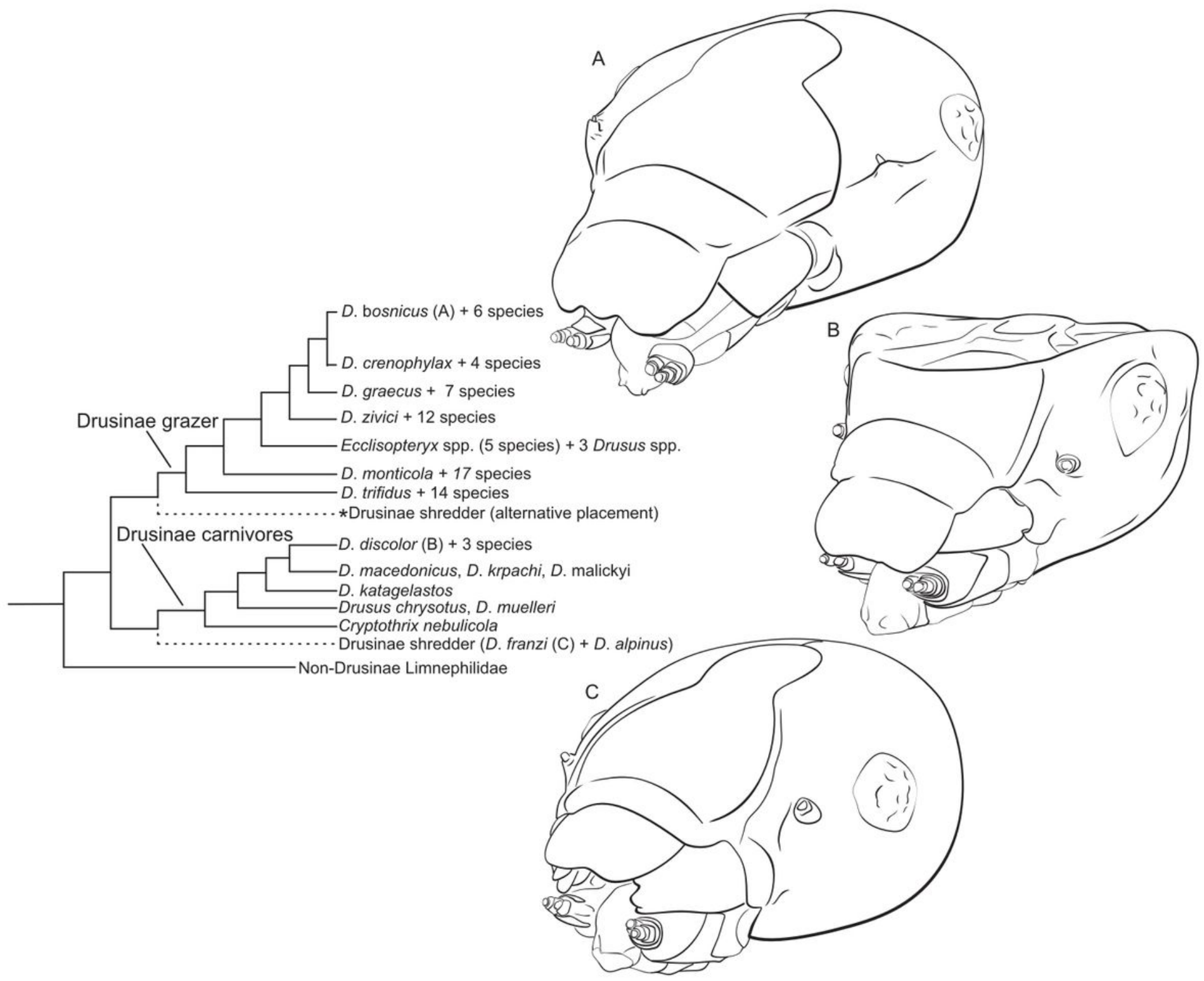

Figure 1

Relationships of Drusinae evolutionary lineages based on published phylogenies 13,14. Drusinae scraping grazers and Drusinae filtering carnivores are monophyla; placement of Drusinae shredders is equivocal as sister of either Drusinae grazers or Drusinae carnivores. Gross head capsule morphology of Drusinae grazers (A, Drusus bosnicus) and Drusinae shredders (C, D. franzi) is quite similar, and differs distinctly from that of Drusinae carnivores (B, D. discolor). Figure not to scale; del. Vitecek. 


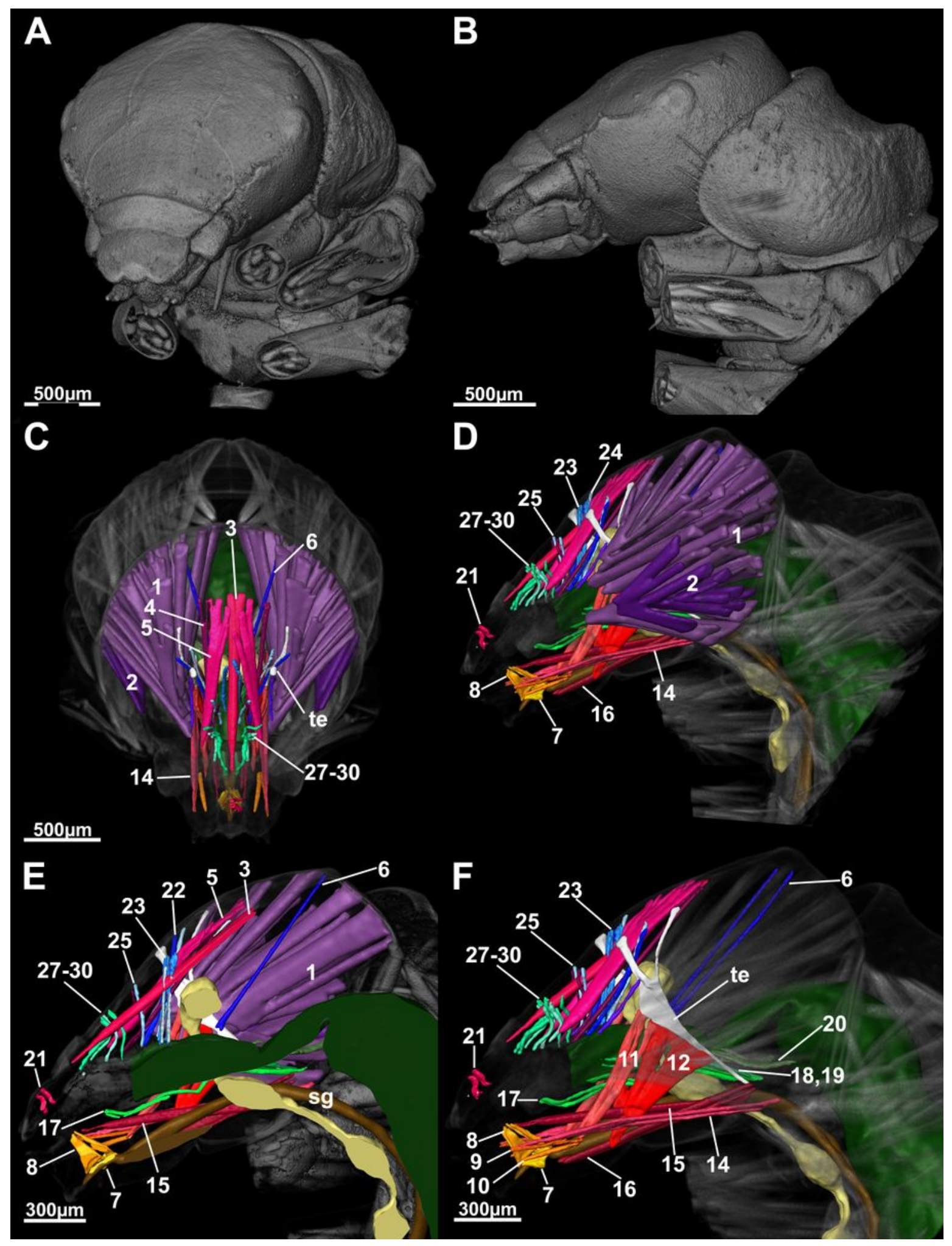

\section{Figure 2}

3D-reconstruction of the internal head anatomy of Drusus bosnicus (5th larval instar) based on $\mu$ CT data. Abbreviations: 1=Musculus cranio-mandibularis medialis, 2=M. cranio-mandibularis lateralis, 3=M. fronto-labralis, 4=M. fronto-pharyngalis, 5=M. fronto-epipharyngalis, $6=\mathrm{M}$. parietalis-oesophagialis, 7= M. praemento-salivaris, $8=\mathrm{M}$. hypopharyngosalivaris, $9 .=\mathrm{M}$. basistipido-dististipitalis lateralis, $10=\mathrm{M}$. basistipido-dististipitalis medialis, 11=M. tentorio-stipitalis, 12=M. tentorio-cardinalis, 14=M. cranio- 
dististipitalis, $15=\mathrm{M}$. cranio-praementalis anterior, $16=\mathrm{M}$. cranio-praementalis lateralis, $17=\mathrm{M}$. craniocibialis, $18=\mathrm{M}$. cranio-pharyngalis anterior, $19=\mathrm{M}$. cranio-pharyngalis posterior, $20=\mathrm{M}$. cranioesophagialis, 21=M. labro-epipharyngalis, 22=M. parieto-pharyngalis lateralis, 23=M. fronto-pharyngalis medialis, 24=M. fronto-pharyngalis lateralis, 25 and $26=\mathrm{M}$. fronto-pharyngalis ventralis, 27 and $28=\mathrm{M}$. clypealis-pharyngalis, 29 and $30=\mathrm{M}$. clypealis-cibarialis, te=tentorium.

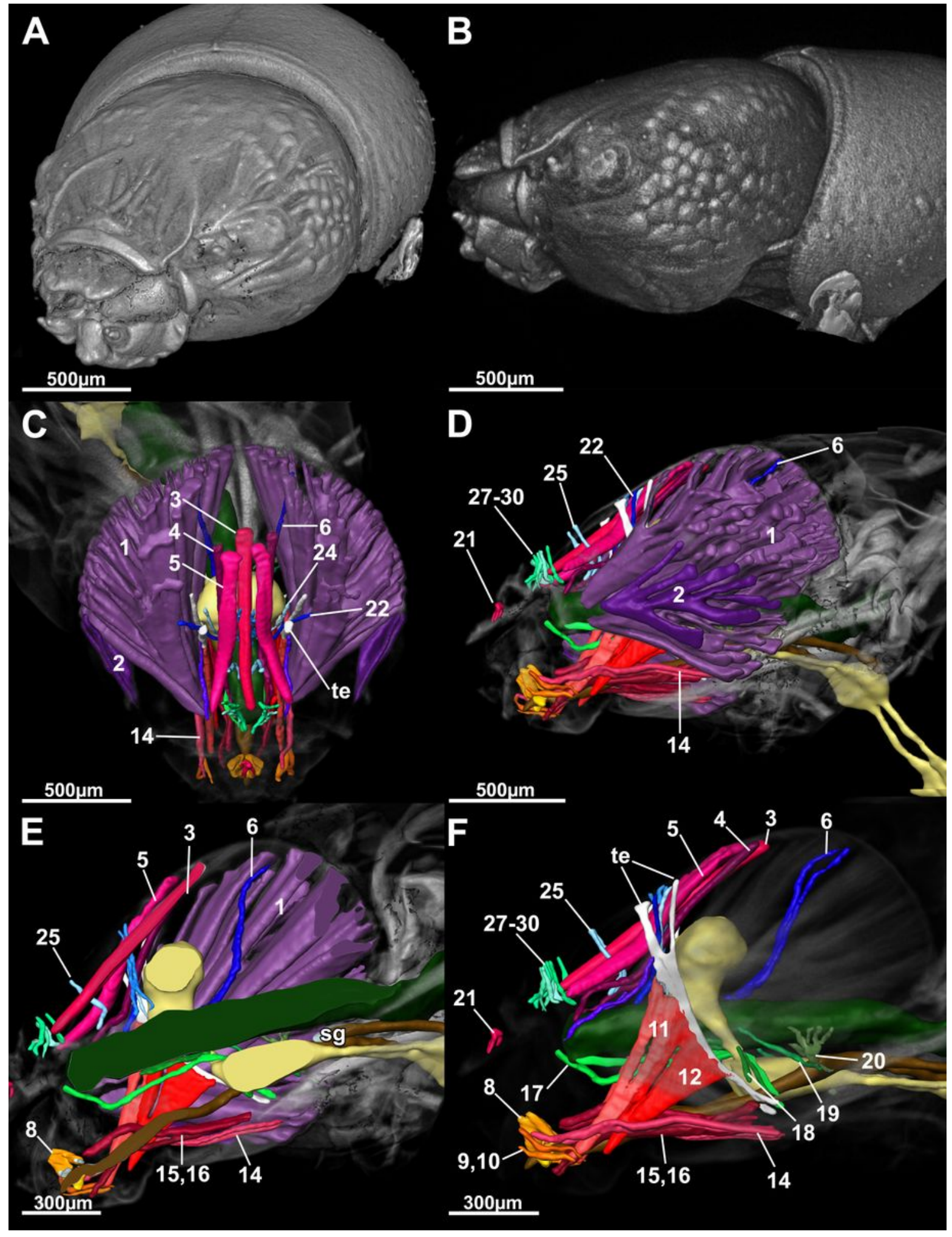

Figure 3 
3D-reconstruction of the internal head anatomy of Drusus franzi (5th larval instar) based on $\mu$ CT data. Abbreviations: $1=$ Musculus cranio-mandibularis medialis, 2=M. cranio-mandibularis lateralis, 3=M. fronto-labralis, 4=M. fronto-pharyngalis, 5=M. fronto-epipharyngalis, $6=\mathrm{M}$. parietalis-oesophagialis, $8=\mathrm{M}$. hypopharyngosalivaris, $9 .=\mathrm{M}$. basistipido-dististipitalis lateralis, $10=\mathrm{M}$. basistipido-dististipitalis medialis, $11=\mathrm{M}$. tentorio-stipitalis, $12=\mathrm{M}$. tentorio-cardinalis, $14=\mathrm{M}$. cranio-dististipitalis, $15=\mathrm{M}$. cranio-praementalis anterior, 16=M. cranio-praementalis lateralis, 17=M. cranio-cibialis, 18=M. cranio-pharyngalis anterior, $19=\mathrm{M}$. cranio-pharyngalis posterior, $20=\mathrm{M}$. cranio-esophagialis, $21=\mathrm{M}$. labro-epipharyngalis, $22=\mathrm{M}$. parieto-pharyngalis lateralis, $23=\mathrm{M}$. fronto-pharyngalis medialis, 24=M. fronto-pharyngalis lateralis, 25 and $26=\mathrm{M}$. fronto-pharyngalis ventralis, 27 and $28=\mathrm{M}$. clypealis-pharyngalis, 29 and $30=\mathrm{M}$. clypealiscibarialis, te=tentorium. 


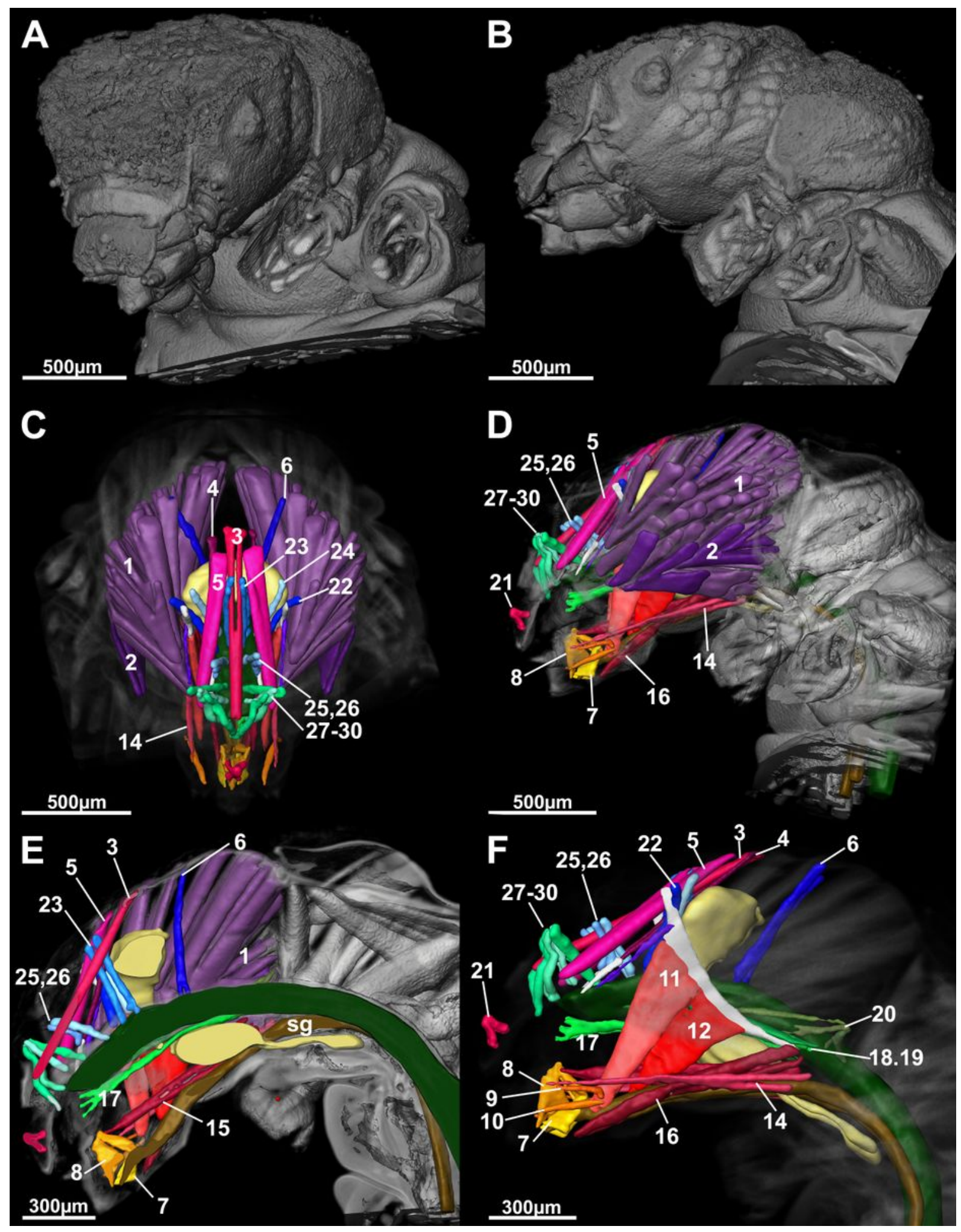

\section{Figure 4}

3D-reconstruction of the internal head anatomy of Drusus discolor (5th larval instar) based on $\mu$ CT data. Abbreviations: 1=Musculus cranio-mandibularis medialis, 2=M. cranio-mandibularis lateralis, 3=M. fronto-labralis, 4=M. fronto-pharyngalis, 5=M. fronto-epipharyngalis, $6=\mathrm{M}$. parietalis-oesophagialis, 7= M. praemento-salivaris, $8=\mathrm{M}$. hypopharyngosalivaris, $9 .=\mathrm{M}$. basistipido-dististipitalis lateralis, $10=\mathrm{M}$. basistipido-dististipitalis medialis, 11=M. tentorio-stipitalis, 12=M. tentorio-cardinalis, 14=M. cranio- 
dististipitalis, $15=\mathrm{M}$. cranio-praementalis anterior, $16=\mathrm{M}$. cranio-praementalis lateralis, $17=\mathrm{M}$. craniocibialis, $18=\mathrm{M}$. cranio-pharyngalis anterior, $19=\mathrm{M}$. cranio-pharyngalis posterior, $20=\mathrm{M}$. cranioesophagialis, 21=M. labro-epipharyngalis, 22=M. parieto-pharyngalis lateralis, 23=M. fronto-pharyngalis medialis, $24=\mathrm{M}$. fronto-pharyngalis lateralis, 25 and $26=\mathrm{M}$. fronto-pharyngalis ventralis, 27 and $28=\mathrm{M}$. clypealis-pharyngalis, 29 and $30=\mathrm{M}$. clypealis-cibarialis, te=tentorium.

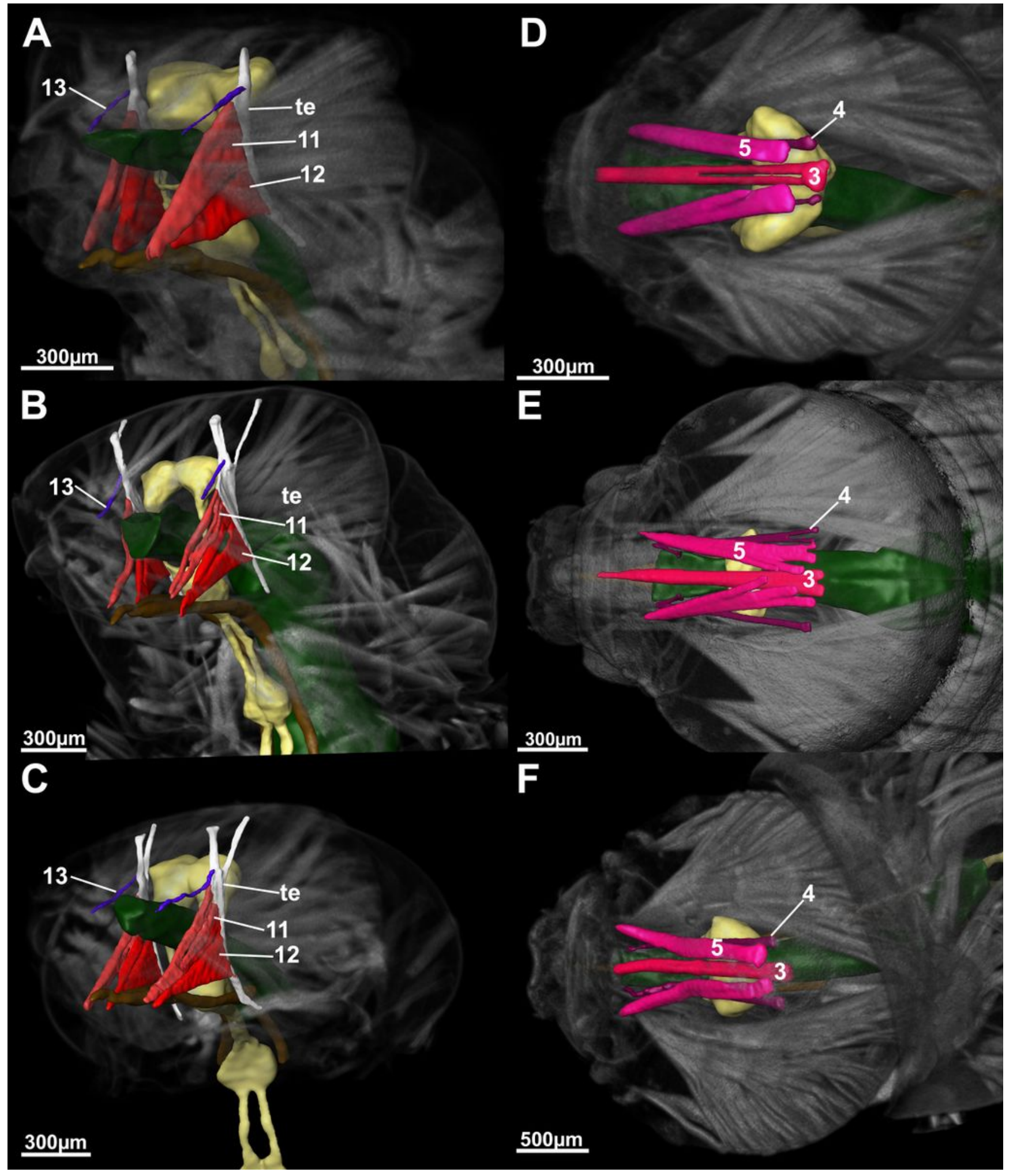

Figure 5 
Comparison of the left ventro-lateral (A-C) and frontal view (D-F) of 5th instar larvae of Drusus discolor (A, $D)$, D. bosnicus $(B, E)$ and $D$. franzi $(C, F)$ based on $\mu C T$ data. Abbreviations: 3=M. fronto-labralis, 4=M. fronto-pharyngalis, $5=\mathrm{M}$. fronto-epipharyngalis, $11=\mathrm{M}$. tentorio-stipitalis, 12=M. tentorio-cardinalis, $13=$ M. tentorio-mandibularis, te=tentorium.

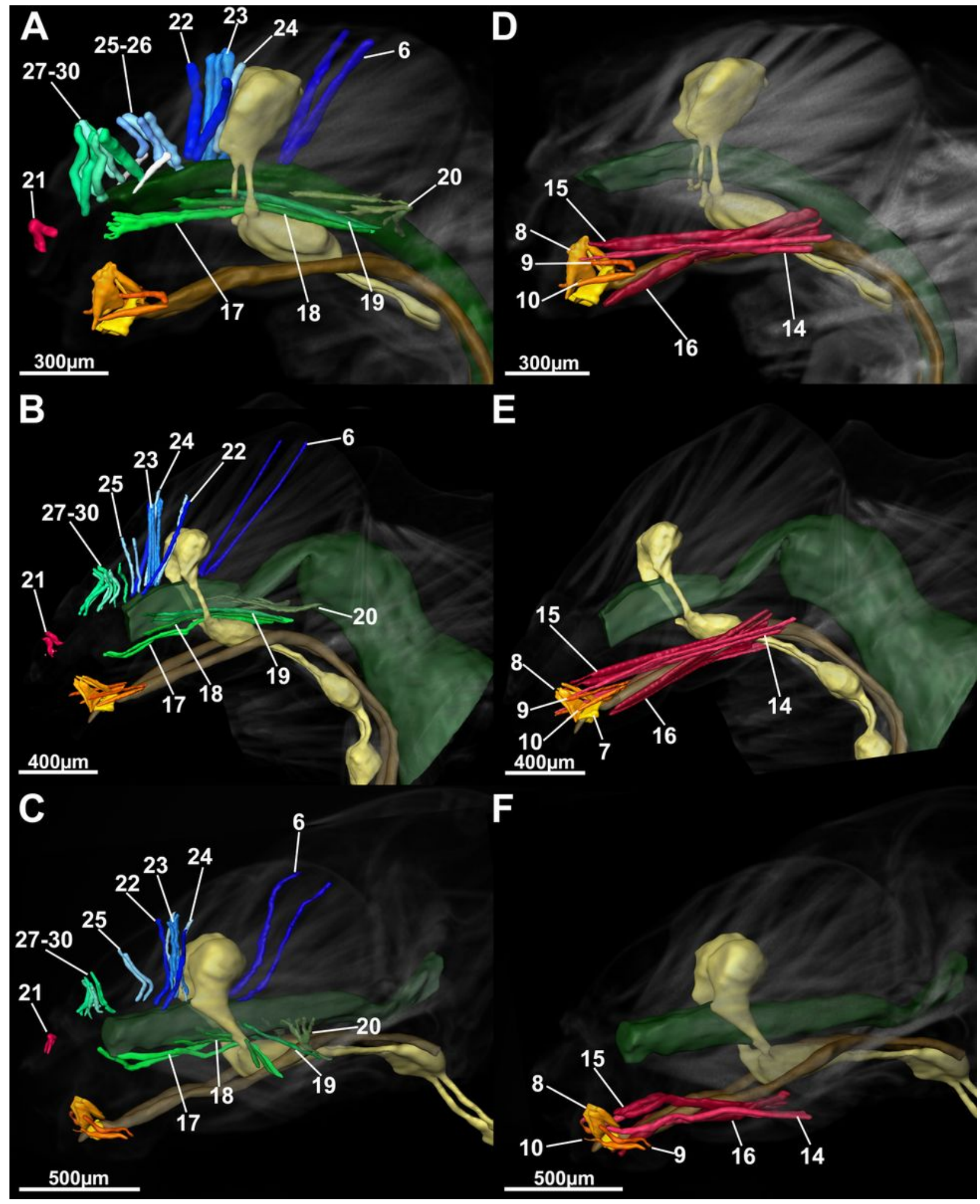

Figure 6 
Lateral view of 5 th instar larvae of Drusus discolor $(A, D)$, D. bosnicus $(B, E)$ and $D$. franzi $(C, F)$ based on $\mu \mathrm{CT}$ data. Abbreviations: $6=\mathrm{M}$. parietalis-oesophagialis, $7=\mathrm{M}$. praemento-salivaris, $8=\mathrm{M}$.

hypopharyngosalivaris, 9.=M. basistipido-dististipitalis lateralis, $10=\mathrm{M}$. basistipido-dististipitalis medialis, 14=M. cranio-dististipitalis, $15=\mathrm{M}$. cranio-praementalis anterior, $16=\mathrm{M}$. cranio-praementalis lateralis, $17=\mathrm{M}$. cranio-cibialis, $18=\mathrm{M}$. cranio-pharyngalis anterior, 19=M. cranio-pharyngalis posterior, $20=\mathrm{M}$. cranio-esophagialis, $21=\mathrm{M}$. labro-epipharyngalis, $22=\mathrm{M}$. parieto-pharyngalis lateralis, $23=\mathrm{M}$. frontopharyngalis medialis, 24=M. fronto-pharyngalis lateralis, 25 and $26=\mathrm{M}$. fronto-pharyngalis ventralis, 27 and $28=$ M. clypealis-pharyngalis, 29 and 30=M. clypealis-cibarialis.

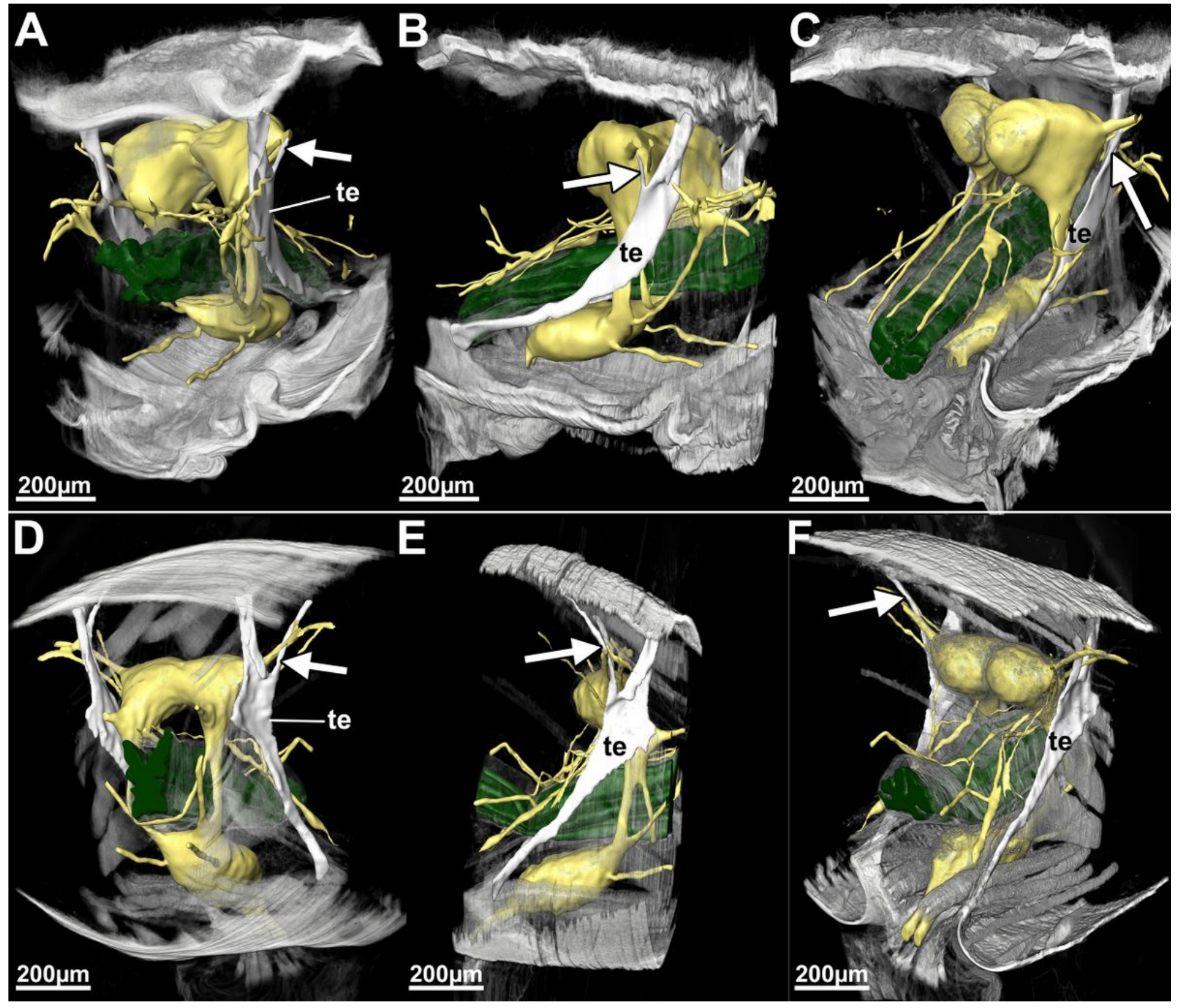

Figure 7

Visualization and comparison of the secondary supratentorial branch of Drusus bosnicus (D-F) which is missing in $\mathrm{D}$. discolor (A-C) (indicated with an arrow) based on histological sections. Abbreviations: 
te=tentorium. central nervous system including cerebral ganglion mass, gnathal ganglion mass, frontal ganglion and innervation patterns in yellow. 